\title{
Capacity of Main Railway Lines - Analysis of Methodologies for its Calculation
}

\author{
Lenka Černá \\ University of Žilina \\ Faculty of Operation and Economics of \\ Transport and Communications \\ Department of Railway Transport \\ Slovak Republic \\ e-mail: lenka.cerna@fpedas.uniza.sk
}

\section{Peter Blaho}

Železnice Slovenskej republiky (ZSR)

Slovak Republic

e-mail: Blaho.Peter@zsr.sk

\author{
Vladimír L’upták \\ Institute of Technology and Business in \\ České Budějovice \\ Faculty of Technology, Department of \\ Transport and Logistics \\ Czech Republic \\ e-mail: luptak@mail.vstecb.cz
}

Peter Šulko
Železnice Slovenskej republiky (ZSR)
Slovak Republic
e-mail: Sulko.Peter@zsr.sk

\section{Summary}

This contribution in a cross section way focused on the analytical determination of practical capacity of main tracks and the issue of the required capacity in the context of the comparison of national methodology used by the ŽSR and the recommended international UIC methodology. Methodology for the calculation of permeable performance within the national conditions is stipulated by ŽSR's regulation D24, the methodology within the international conditions for members of the UIC railway union is recommended by UIC Code 406 . Both of presented methodologies have their pros and cons, which are consistently derived from this text.
\end{abstract}

DOI 10.17818/NM/2018/4SI.9

UDK 625.1:656.2

$656.2: 338.485 .2$

Original scientific paper

Paper accepted: 28. 8. 2018.

\section{KEY WORDS}

capacity

methodology

timetable

reserve

capacity consumption

\section{INTRODUCTION}

"The capacity of the railway infrastructure is determined by the number of train paths that can be planned over a certain period of time on a certain part of the railway infrastructure due to the heterogeneity of the train types and the required quality of the train transport" [1], [2].

In rail transport and in terms of our conditions it is usual to call the capacity of the track "permeable performance of track" or alternatively in abbreviated term "track permeability". The practical permeable performance of track (or track section) indicates the maximum number of train traffic (expressed in number of train paths) that can be set for the track taking into account the time required to carry out inspections, maintenance or planned renovations of the facilities and also the time necessary to compensate for the delays caused by irregularities and failures in rail transport [3-4].

Methodology for the calculation of permeable performance within the national conditions is stipulated by ŽSR's regulation - D24 [2], the methodology within the international conditions for members of the UIC railway union is recommended by UIC Code 406. In this contribution, we will deal with the analytical determination of the practical permeability of the track and its required quality in the context of comparison of the methods stipulated in the above mentioned documents.

The methodology of measuring the customer satisfaction with the provided services in logistics enterprise is proposed by the several steps. The proposal of methodology utilizes the customer questionnaire survey as well [4].

\section{METHODOLOGY OF THE ŽSR - D24}

In the Slovak railway transport operation, the methodology of the regulation ŽSR D 24 is applied. Such regulation establishes relations for calculation of both quantitative and qualitative indicators of permeability performance.

Practical track permeability $n_{\text {prakt }}$ expressed in the number of trains for the calculation time, is calculated according to the formula [5]:

$$
n_{\text {prakt }}=\frac{T-\left(T_{v y l}+T_{\text {stal }}\right)}{t_{o b s}+t_{\text {medz }}} \quad\left[v l . T^{-1}\right]
$$

where variables in formula relate to the track (or track section) are:

$\mathrm{T}$ - calculation time for which permeable performance of track is calculated [min]

$\mathrm{T}_{\mathrm{vyl}}$ - total time in which the track in the calculation time is excluded from service for the purpose of maintenance, repair [min]

$\mathrm{T}_{\text {stal }}$ - total time of constant manipulation, i.e. the time at which the track during the period " $T$ " is occupied by other activities than that in which its permeable performance is detected [min] $t_{\text {obs }}$ - average time of occupancy of the track by average train [min]

$\mathrm{t}_{\text {medz }}$ - average time of gaps for one average train [min]

Following this quantitative indicator, we evaluate the practical track permeability also by qualitative indicators, which are in particular the degree of occupancy so and the usage of permeable performance Kprakt. 
where:

$$
S_{O}=\frac{T_{o b s}}{T-\left(T_{v y l}+T_{\text {stal }}\right)} \quad[-]
$$

$\mathrm{T}_{\mathrm{obs}} \quad$ - total time of occupancy of track [min]

$$
K_{\text {prakt }}=\frac{N_{\text {prav }}}{n_{\text {prakt }}} \cdot 100 \quad[\%]
$$

where:

$\mathrm{N}_{\text {prav }}$ - total number of regular trains [vl.T-1]

Usage of practical permeable performance Kprakt based on formula (3) is calculated by using number of trains as the unit of measurement - (during the reference period). However, by putting the formula (3) into formula (1) and its modification), we get a formula for the calculation of the practical permeable performance Kprakt by time as the unit of measure:

$$
K_{\text {prakt }}=\frac{T_{\text {obs }}+T_{\text {medz }}}{T-\left(T_{\text {vyl }}+T_{\text {stal }}\right)} \cdot 100 \quad[\%]
$$

A sufficiently occupied timetable is considered the one with degree of occupancy in a range of 0.5 to 0.67 . Normative permeability is defined as use of practical permeability $\mathrm{K}_{\text {prakt }}$ by regular transport in the range of $80-90 \%$.

These qualitative indicators therefore constitute an optimal boundary between the acceptable use of infrastructure capacity and time reserves (backups) needed in particular to compensate for the delays caused by irregularities and failures in rail transport, as well as for reasons stated in the literature for the average additional time $t_{\text {dod }}$ and average time of probable disturbances of rides $t_{\text {rus }}$. The parameter that evaluates and secures the abovementioned balance and thus the quality of the timetable is the gap time (e.g., in relation (1) $\mathrm{t}_{\text {medz }}$ ) also called timetable backup.

Recommendation stated in regulation ŽSR D24 takes into account both, the character of the track section and the time of occupation. Time backup (gap) $t_{\text {medz }}$ is recommended for operating conditions difficult (A), normal (B) and simple (C) depending on the time while the track section is occupied by train. Overview of recommended times for gaps, as well as their percentage share, in connection to the occupancy time is stated in Table 1.

\section{FLOWCHART REGARDING THE SELECTION OF THE CRITERIA}

Determining the set of criteria is based on the proposed flowchart. It is verified by applying the flowchart containing the criteria which are crucial for measuring the customer satisfaction with the provided logistics services [6-8].

Flowchart is created based on the real observations of the logistics processes in the selected companies. The consecutive steps of the selection of criteria are shown in the flowchart. Definition of the process (problem) represents the first step of creating the flowchart. Definition of the relevant tasks of the process: monitoring and understanding the accurate records of process represents next step [9-11].

Figure 2 shows the graphical representation of selecting the criteria for measuring the customer satisfaction [12].

From Table 1 it is evident that with the increasing $t_{\text {obs' }}$ the value of the $t_{\text {medz }}$ increases too, but in a slower pace. This character can also be expressed by the regression correlation equation, whose shape is also shown in Figure 1.

Table 1 Required gap times according to the regulation of ŽSR D 24 and their share to the occupancy time

\begin{tabular}{|c|c|c|c|c|c|c|}
\hline & \multicolumn{2}{|c|}{$t_{\text {obs }}$} & A & $t_{\text {medz }}=t_{\text {dod }}+t_{\text {rus }}[\mathrm{min}]$ & \multicolumn{4}{|c|}{ proportion $t_{\text {medz }}$ to $t_{\text {obs }}[\%]$} \\
\hline 5 & 4.7 & B & C & A & B & C \\
\hline 6 & 5.1 & 2.5 & $94 \%$ & $62 \%$ & $50 \%$ \\
\hline 7 & 6.6 & 3.8 & 2.9 & $95 \%$ & $63 \%$ & $48 \%$ \\
\hline 8 & 7.4 & 5.4 & 3.4 & $94 \%$ & $63 \%$ & $49 \%$ \\
\hline 9 & 8.3 & 5.5 & 4.8 & $93 \%$ & $63 \%$ & $48 \%$ \\
\hline 10 & 9.1 & 6.1 & 4.6 & $91 \%$ & $61 \%$ & $47 \%$ \\
\hline 11 & 10.0 & 6.7 & 5.0 & $91 \%$ & $61 \%$ & $45 \%$ \\
\hline 12 & 10.8 & 7.2 & 5.4 & $90 \%$ & $60 \%$ & $45 \%$ \\
\hline 13 & 11.6 & 7.8 & 5.8 & $89 \%$ & $60 \%$ & $45 \%$ \\
\hline 14 & 12.4 & 8.3 & 6.1 & $89 \%$ & $59 \%$ & $44 \%$ \\
\hline 15 & 13.1 & 8.8 & 6.5 & $87 \%$ & $59 \%$ & $43 \%$ \\
\hline
\end{tabular}

Source: authors, based on [12], [13]

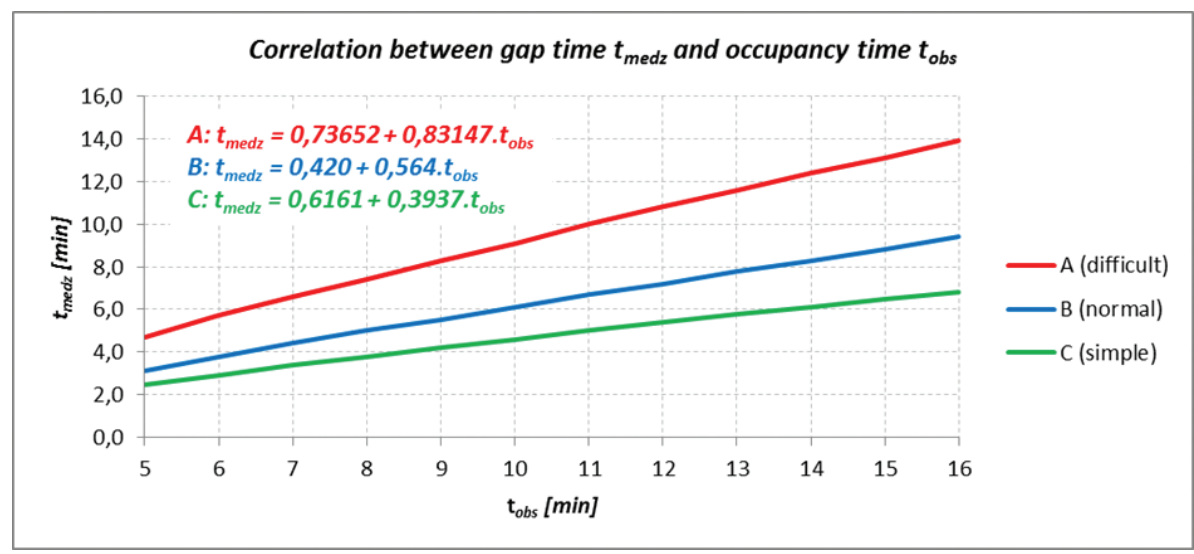

Source: [13]

Figure 1 Correlation between gap time and occupancy time 
If the calculated value of the average gap time $t_{\text {medz }}$ for one average train (from formula (1)) is lower than the recommended value according to the regulation ŽSR D 24 (Table 1), then there is a high risk of endangering the quality of timetable and its planned feasibility.

\section{METHODOLOGY OF UIC 406}

For the purpose of international comparability of permeable performance, i.e. railway infrastructure capacity, between individual infrastructure managers, the UIC Railway Union declared the methodology recommended in UIC Code 406 Capacity [13].

According to this methodology, the utilization of the capacity on the track section and within the calculated period is referred to as "capacity consumption".

Capacity consumption $=\frac{\text { occupancy time }+ \text { Additional times }}{\text { Defined time period }} \cdot 100[\%]$

In this case, the optimal boundary between the use of infrastructure capacity and time reserves (backups), i.e. meaningfully the same as $t_{\text {medz }}$ in the ŽSR D 24 methodology, represents an additional time rate.

The criteria necessary for determining and assessing the "optimal" additional time are based (as well as in case of gap times $t_{\text {medz }}$ in the ŽSR methodology) on the operating characteristics of the existing timetables, or actual delays. However, extrapolation of time series may be time consuming, if not impossible. For this reason, the standard value of the occupancy time rate was determined as an expression of the required level of quality of the services provided and is given in percentage expression:

$$
\text { Occupancy time rate }=\frac{\text { Occupancy Time }}{\text { Defined Time Perion }} \cdot 100[\%]
$$

In the process of congestion of train paths, UIC 406 Decree recommends the standard values of the occupancy time rates by type of traffic on the track as follows:

Table 2 Proposed occupancy time rates

\begin{tabular}{|l|c|c|}
\hline \multicolumn{1}{|c|}{ Type of line } & Peak hour & Daily period \\
\hline Dedicated suburban passenger traffic & $85 \%$ & $70 \%$ \\
\hline Dedicated high-speed line & $75 \%$ & $60 \%$ \\
\hline Mixed-traffic lines & $75 \%$ & $60 \%$ \\
\hline Source: authors, based on [13] & &
\end{tabular}

Following the occupancy time rate, the recommended values of the additional time rates derived from the occupancy time rates are shown in the following table 3 :

$$
\text { Additional Time Rate }=\left[\frac{100}{\text { occupancy Time Rate }}-1\right] \cdot 100 \quad[\%]
$$

Table 3 Proposed additional time rates for lines

\begin{tabular}{|l|c|c|}
\hline \multicolumn{1}{|c|}{ Type of line } & Peak hour & Daily perion \\
\hline Dedicated suburban passenger traffic & $18 \%$ & $43 \%$ \\
\hline Dedicated high-speed line & $33 \%$ & $67 \%$ \\
\hline Mixed-traffic lines & $33 \%$ & $67 \%$ \\
\hline
\end{tabular}

Source: authors, based on [13]

Capacity consumption values reflect the basic concepts of capacity expressed through the timetable properties of individual train paths and therefore are used to identify the bottlenecks. Therefore, the assessment of the capacity consumption (as well as the recommended ratio between the occupancy time rate and the additional time rate) is made according to the formula:

Capacity Consumption $=\frac{\text { Occupancy time } \cdot(1+\text { Additional Time Rate) }}{\text { Defined Time Period }} \cdot 100$ [\%] (8)

From the formula (6), it is obvious that with the increasing occupancy time the occupancy time rate logically increases too, while it is evident from the formula (7) that with the increasing occupancy times the value of the additional time rate decreases. Thus, the dependence of the occupancy time rate and of the additional time rate from the occupancy time during the defined time period can also be expressed graphically [13].

In figure 2 and figure 3, there are for the defined time period 1440 minutes, displayed recommended limits for the (most widely spread) mixed-traffic lines as are indicated in Tables 2 and 3. Limit values indicated in the graphs and their direction are marked by red.

It can be stated that if the capacity consumption value is below the $100 \%$ limit, the part of capacity is still unused. Otherwise, if the recommended limit values are exceeded (for example, Table 2 and 3, Figure 2, then there is a high risk of endangering the quality of timetable and its planned feasibility [14].

The balance between the utilized capacity consumption and the recommended limit rates is set to use the whole defined time period and thus the capacity consumption up to $100 \%$. This argument is also proven by the formula in which we put into equality formula (5) and formula (8). Subsequently, we put formulas (6) and (7) into a formula (8) and simplify the resulting formula (9) to (10). Special attention should be paid the the unit
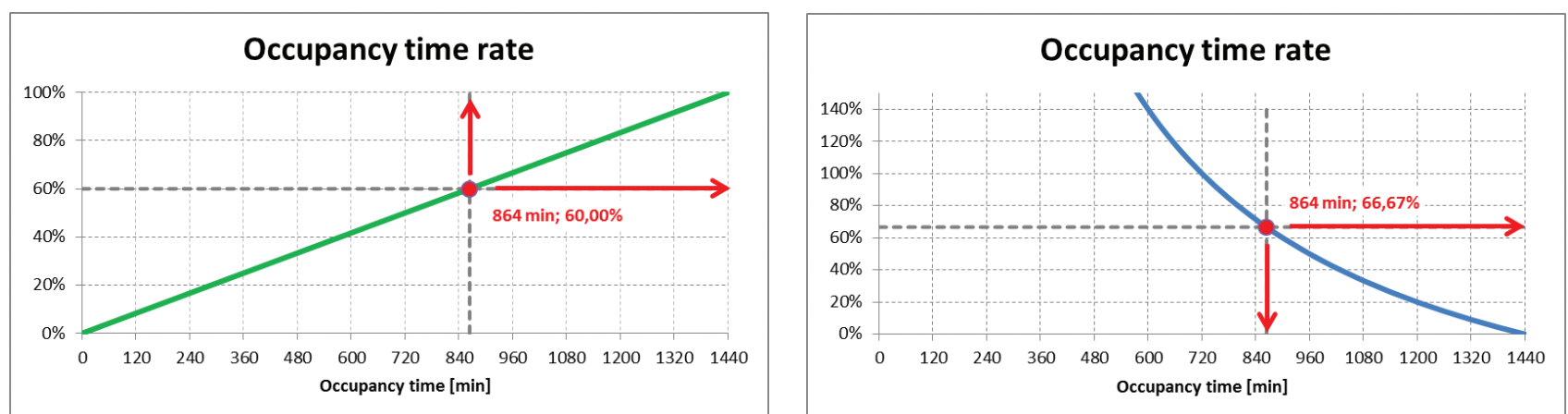

Source: [14]

Figure 2 Occupancy time rate and Additional time rate 
equivalence, i.e. transfer and correct placement of percentages on numerical values.

$$
\frac{T_{o b s}+T_{d o d}}{T}=\frac{T_{o b s} \cdot\left(1+\frac{1}{\frac{T_{o b s}}{T}}-1\right)}{T}
$$

where we have shortened the original tags due to the length of the relationship as follows:

$\mathrm{T}_{\mathrm{obs}}=$ Occupancy time [min]

$\mathrm{T}_{\mathrm{dod}}=$ Additional times [min]

$\mathrm{T}=$ Defined time period [min]

$$
T_{\text {obs }}+T_{\text {dod }}=T
$$

\section{COMPARABILITY OF ŽSR AND UIC METHODOLOGIES}

The presented methodologies for calculating and assessing the permeable performance of the track use different methods of calculation to achieve their results (utilization or capacity consumption), although by apparently different parameters, they are ultimately mutually comparable.

Therefore, in the sample example we calculate the capacity of the track with normal conditions i.e. mixed train traffic in $(T)$ 1440 minutes ( 24 hours) if we the number of expected trains $(N)$ 45 trains with an average occupancy time $\left(t_{\text {obs }}\right) 12$ minutes per train [14].

Calculation according methodology of ŽSR D 24:

defined time period $\mathrm{T}=1440 \mathrm{~min}$,

occupancy time $T_{\text {obs }}=540 \mathrm{~min}$,

gap time (according table $1=7.2 \mathrm{~min}$ per 1 train) $=324 \mathrm{~min}$, practical track permeability [according (1)] $n_{\text {prakt }}=75$ trains, degree of occupancy [according (2)] so $=0.375$,

usage of permeable performance [according (3), as well as (4)] $\mathrm{K}_{\text {prakt }}=60 \%$.

Calculation according UIC 406:

defined time period $\mathrm{T}=1440 \mathrm{~min}$,

occupancy time $\left(T_{\text {obs }}\right)=540 \mathrm{~min}$,

additional time $\left[\mathrm{T}_{\text {dod }}\right.$ according (10) $]=900 \mathrm{~min}$,

capacity consumption [according (5)] $=60 \%$,

occupancy time rate [according (6)] $=37.5 \%$,

additional time rate [according (7)] $=166.67 \%$,

capacity consumption [according (8)] $=100.01 \%$.

The total time of track occupancy consists of the sum of the partial times of the occupation of individual trains, and it serves also as the basis for the ŽSR methodology. However, if for some reason we only knew the total occupancy time (just like the UIC methodology), we would determine the total required gap time by the regression correlation equation shown in figure 2 . Then, from our example the time of occupation, $T_{\text {obs }}=540 \mathrm{~min}$ and based on the formula $t_{\text {medz }}=0.420+0.564 . t_{\text {obs' }^{\prime}}$ the total gap time $T_{\text {medz }}=304.98 \mathrm{~min}$ and consequently the use of permeable performance will be

$\mathrm{K}_{\text {prakt }}=58.68 \%$. The slight deviation between these values and the values based on ŽSR methodology, is caused by estimation of the regression correlation equation parameters, which has the reliability value $\mathrm{R} 2=0.999$ [15-18].

\section{CONCLUSION}

Both presented methodologies have their pros and cons, which are consistently derived from this text. Despite different calculation methods, both methodologies have the same results (i.e., numerical versus percentage), declaring degree of occupancy according to (2), respectively the occupancy time rate according to (6), as well as the use of the permeable performance according to (3), (4) or capacity consumption according to (5).

As a result, we can conclude that the calculation of the practical permeability of the track can still be performed according to the domestic methodology according to the ŽSR D24 regulation.

The proposed limit values for the occupancy time rates (Table 2) in the context of the degree of occupancy expressed in percentage, as well as the additional time rate (Table 3 ) in the context of the gap times expressed in proportion to the occupancy time in percentage (Table 1), are according to the UIC methodology 406 towards ŽDR D24 methodology for the calculation of track permeability only slightly more stringent. This small difference is practically acceptable, so we can continue to perform the assessment limits of these indicators (degree of occupancy, gap time) according to the domestic methodology according to ŽSR D24

\section{Acknowledgement}

The paper was supported by the VEGA Agency, Grant No. $1 / 0019 / 17$ "Evaluation of regional rail transport in the context of regional economic potential with a view to effective use of public resources and social costs of transport", at Faculty of Operations and Economics of Transport and Communication, University of Žilina, Slovakia.

\section{REFERENCES}

[1] Gašparík J., Šulko P. Technológia železničnej dopravy - líniové dopravné procesy (in the slovak name), EDIS, 1., University of Zilina. 2015. ISBN 97880-554-1171-2.

[2] Galvan, G., Agarwal, J. Community Detection in Action: Identification of Critical Elements in Infrastructure Networks, Journal of Infrastructure Systems, 2018, Vol. 24, Issue 1. https://doi.org/10.1061/(ASCE)IS.1943-555X.0000400

[3] Kałkowska, E. The role of stray currents in the evolution of damage in transport systems. Scientific Journals of the Maritime University of Szczecin, 2016, Vol. 48, No. 120, pp. 134-137. DOI: 10.17402/186.

[4] Dlugoš, M., Pečený, L., Meško, P., Šulko, P. The Impact of Delays of Freight Trains in JIT System Example One Track Line, LOGI 2017- MATEC Web of Conferences, 2017, Vol. 134. https://doi.org/10.1051/matecconf/201713400011

[5] Gašparík, J., Zitrický, V. A new approach to estimating the occupation time of the railway infrastructure, Transport, Vilnius gediminas tech univ, Sauletekio al 11. https://doi.org/10.3846/transport.2010.48

[6] Dolinayová, A., Čamaj, J., Kanis, J. Charging railway infrastructure models and their impact to competitiveness of railway transport, Transport problems, 2017, Vol. 12, Issue 1. https://doi.org/10.20858/tp.2017.12.13

[7] Dolinayová, A., Loch, M. Controlling Instruments Used for Monitoring and Evaluation Processes in the Rail Freight Companies, International scientific conference: business economics and management (Bem 2015), 2015, Vol. 34. https://doi.org/10.1016/S2212-5671(15)01608-1

[8] Lendel, V., M. Varmus. Railway intelligent transportation system - architecture and implementation. Logi - Scientific Journal on Transport and Logistics, 2012, Vol. 3, No. 2, pp. 21-34. ISSN 1804-3216.

[9] Kampf, R., Stopka, O., Kubasáková, I. Macroeconomic Evaluation of Projects Regarding the Traffic Constructions and Equipment, World multidisciplinary civil engineering-architecture-urban planning symposium 2016. https://doi. org/10.1016/j.proeng.2016.08.623

[10] Luupták, V., Gašparík, J., Chovancová, M. Proposal for evaluating a connection quality within transport networks, MATEC Web of Conferences, 2017, Vol. 134 Art. num. 00033. https://doi.org/10.1051/matecconf/201713400033 
[11] Gašparík, J., L’upták, V., Kurenkov, P.V., Meško, P. Methodology for assessing transport connections on the integrated transport network. Communications Scientific Letters of the University of Zilina, 2017, Vol. 19, Issue 2. ISSN 1335-4205.

[12] Gašparík, J., Abramović, B., Halás, M. New graphical approach to railway infrastructure capacity analysis, Promet - Traffic - Traffico, 2015, Vol. 27, Issue 4. https://doi.org/10.7307/ptt.v27i4.1701

[13] UIC CODE 406. Capacity, 2nd edition, International union of railways (uic) Paris 2013. ISBN 978-2-7461-2159-1.

[14] ŽSR D 24. Prescriptions for recognition of the relevance of railway treatments, NADAS Praha 1966.

[15] Abramovic, B., Zitrický, V., Meško, P. Draft methodology to specify the railway sections capacity. Logi - Scientific journal on transport and logistics, 2017, Vol. 8, No. 1, pp. 1-10. https://doi.org/10.1515/logi-2017-0001
[16] Bevrani, B., Burdett, R. L., Bhaskar, A., Yarlagadda, P. K. D. V. A capacity assessment approach for multi-modal transportation systems. European Journal of Operational Research, 2017, Vol. 263, Issue 3, pp. 864-878. https:// doi.org/10.1016/j.ejor.2017.05.007

[17] Hokstok, C. Application framework of value stream costing (vsc) for supporting rail infrastructure controlling. Logi - scientific journal on transport and logistics, 2013, vol. 4, no. 1, pp. 63 - 80, ISSN 1804-3216.

[18] Oroojlooyjadid, A., Eshghi, K. Train timetabling on double track and multiple station capacity railway with useful upper and lower bounds. Scientia Iranica, 2017, Vol. 24, Issue 6, pp. 3324-3344.https://doi.org/10.24200/sci.2017.4396 